\section{Marine census nets wealth of unknown ocean life}

Giant sea stars and bacteria that can grow to several centimetres long are among more than 5,600 marine species that scientists have discovered during work on the first comprehensive global marine-life census. The census, which began in 2000 and should be completed by 2010 , has also provided evidence that many of the world's deep-sea octopuses evolved from a common ancestor, of which a close relative, Megaleledone setebos (pictured), still lives in the Southern Ocean.

The most recent findings from the 2,000-strong international team of marine scientists behind the effort were presented at the World Conference on Marine Biodiversity in Valencia, Spain, which began on 11 November.

\section{Research agency focuses on first-time applicants}

Elias Zerhouni, former director of the US National Institutes of Health (NIH), spent his last day in the job helping young scientists. On 31 October, he created a formal regulation out of what has been a de facto policy for the past two years aimed at reversing a steady decline in the number

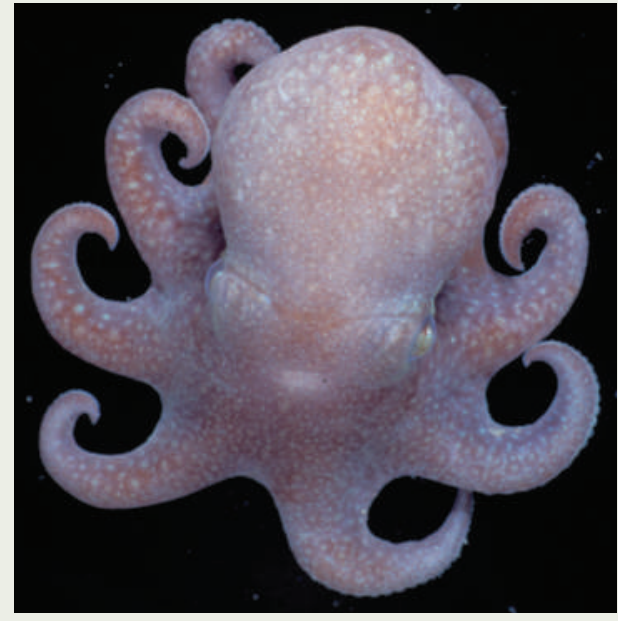

of young investigators securing the agency's bedrock $\mathrm{R} 01$ research grants.

The regulation means that first-time grant applicants won't be competing directly against seasoned investigators. Instead, the agency will "wherever possible" conduct initial peer review on applications from new investigators separately.

The agency expects that the policy will mean that at least 1,650 new investigators will receive awards in 2009 - up from a decade-long nadir of 1,354 grants in 2006. Since 1980, the average age at which researchers receive their first NIH grant has climbed from 37 to 42 .

\section{Billion-dollar bid for stem-cell treatments}

Genzyme, a biotechnology company based in Cambridge, Massachusetts, announced last week that it will invest up to US\$1.4 billion in two adult stem-cell therapies being developed at Osiris Therapeutics.

Osiris, which is headquartered in Columbia, Maryland, is conducting latestage clinical trials using mesenchymal stem cells harvested from bone marrow and grown in large-scale cultures. Genzyme will pay $\$ 130$ million up front for the rights to commercialize the products and will fund $40 \%$ of the cost of future phase III and IV clinical trials, with the remainder of the sum as milestone and royalty payments.

The first therapy, Chondrogen, is intended to treat osteoarthritis in the knee. The second, Prochymal, has already been approved by the US Food and Drug Administration as a last-ditch treatment for children with a potentially deadly immune response to tissue transplantation called graft-versus-host disease. 